\title{
Covid19 Bill, What We Paid So Far \& What We Have To Pay Latter
}

\section{Hussain HY*}

Research Studies and data analysis dept, Dubai Health Authority, United Arab Emirates

*Corresponding author: Hussain HY, Dubai Health Authority, Research Studies and data analysis dept, Dubai, United Arab Emirates, Tel: 00971502608873; Email: Hyhussain@dha. gov.ae

\section{In sighting Crisis Contexts}

It is now necessary for everyone to realize that the stage of shock caused by the COVID 19 is not resolved, yet it will do so shortly, which will not happen without high and painful price, this crisis remarkably uncovers the fragility status of the international system and hard to resilience capacity has that we all deceived by. The accumulated gains throughout decades and decades humankind added has been demolished down in weeks and days., and revealed an absolute lack of preparedness and insight during the witnessed crisis, some of the countries were totally torn and collapsed with the at the very first challenge. The time has come for the emerging of a new world, with different capacities, values, and visions. In addition, uncertainty spaces need to be narrowing. The current question is should we go back to our normal life or shall we understand lessons deeply to develop a new world.

\section{How will Covid19 Change the World's} Status?

Thousands and millions of people around the world perhaps will be out of work. Enormous economy stimulus packages will be pushed by the national government ever in the present history. In certain places, property owners will not be collecting rent, or banks collecting mortgage payments and the homeless will be allowed to stay in hotels free of charge. Direct government Basic income provision trials will be executed. in the large swathes of the world will be collaborating - with various degrees of coercion and nudging - on a shared project of keeping at least two meters between each other whenever possible. However, crises can also send societies down darker paths. , government surveillance of citizens exploded.

\section{Endless Questions to be Addressed}

As current crises shape our history, there are hundreds of thinkers who have devoted their lives to studying how they unfold. Apparently, crisis studies fields revealed the potentials and the power to-mapping the way the community is laid bare, wherever and whenever likewise crisis placed in a given community, the fundamental scenario will be based on who have less and who have more. What capacity and how long it stays. What fear people and what makes people treasured. In similar historical times, hunting small stories and images shall tragically reveal, what has been broken in the community, as just how broken it is, in the shape of tiny images and stories.

\section{The Crisis that is Shaping Current \& Future Life}

In the few passed months, countless numbers of news has informed us. Large numbers of flights were flight empty or almost similar to that, only in aiming to maintain slots on main routs intact in sky. There have been reports of police fining homeless people for being outside during the lockdown. Prisoners are getting paid less than a dollar per hour to bottle hand sanitizer that they themselves are not allowed to use (because it contains alcohol), in a jail , where soaps must be bought, but never provided freely , but must buy it in an on-site shop. However, disasters and emergencies do not just throw light on the world as it is. But tears the coherent fabric of normal life. Through opened up holes, possibilities of other worlds can be glimpsed. Many of crises insight lookers concentrate more on bad consequences scenarios. By making bad things even worse. In crisis times, particularly, tendencies to stepping up xenophobia and racial 


\section{Epidemiology International Journal}

scapegoating remarkably increase. Recent publications e.g. Wikipedia revealed that incidences of "xenophobia and racism during 2019-20 Covid19 pandemic from even more than 35 countries" reported: "In a wise enough and civilized world, assumptions that global pandemic must drive to greater internationalism would be expected ", by accelerating up manufacturing of test kits, masks, and respirators, basic essential supplies -- and spare then for poorer countries, not only rich.

\section{One Battle One World}

It is all one battle. However, it is not necessarily a rational world. Therefore, there could be a lot of demonization and calls for isolation: means more and more mortalities, morbidities, and worldwide suffering. "It claimed or implied that Covid-19 is a man-made bioweapon. Officials, in turn, have pushed the conspiracy theory that the outbreak came from Laboratories. In Europe, some officials declared "Europe e.g. confronting a double war at front lines, war of migration and war of Covid19 pandemic. Both and each of them is movement spread phenomena. However, it is easy, in the rush of crisis, to put in place surveillance tools without thinking about the long-term harm they might do. "The natural evolution of the current emergency reflected obvious shifting of paradigm- to be what ways to secure firms in order to be able to make better data collection? Instead of 'How do we controlee such companies not to violating privacy norms and rights'

\section{Covid19 Bill}

One of the major parts of the Covid19 bill is to give police and immigration officers the authority - in place for the next two years - to arrest and suspected Covid19, infected people, to enforce testing. Similar rules shall allow judges to exempt courtrooms in the context of emergency times, leading to a status of people being put in jail even without given an opportunity to object formally. These powers are put in place, and it sounds reasonable enough at the time and then very quickly they are applied for other purposes that have nothing to appreciate public safety and democracy.

\section{Addressing Public Health by Governments}

The present crisis experiences the high demand to meet public health concerns by "Governments adopting approaches more suitable for criminals tracking. Likewise, confused mindset ended up most impacting poor and racial minorities. Similar solutions can effectively contribute confronting illnesses stronger, through mobilizing scarce resources to be shared between citizens and government of distrust between government and citizens. As the report put it: People, rather than the disease, become the enemy. "With the broad public giving up a great deal while a small few profited - Covid-19 might open the door to political progress.

\section{New World}

The question of is this: Covid-19 has revealed the political status quo to be broken. Long before anyone had heard of the news is this: Covid-19 has revealed the political status quo to be broken. Previous to the era of Covid19, people used to die of kind of diseases that we used to deal with their treatment and prevention. For a long time, People experienced risky lives in community's colored with wealth. Crisis threats have been told long back by experts to be on the doors, like pandemics, yet preparedness strategies were not put in a place for long. "Health services as well as the essential expenses of living like accommodation -extensive governmental solution will not be available. Instead, it has been told that what works best are "marketplace" solutions, which give large roles to corporations motivated not by outdated notions like "the public good" but by a desire to make a profit. As Covid19 outbreak started to spread out, national authorities pushed billions in days -farther to that, cheques to citizens have been directly delivered, what was feasible From this perspective, the task today is not to fight the virus in order to return to business as usual, because business, as usual, was already a disaster. Optimistic thinkers realized that there is a big hope that we might start to see the new world. To fight thecovid19, to transform the business into something more secure and humane.

\section{Global Burdens}

In spite of being the biggest global crisis since the Second World War, Covid19 is still tiny comparing to longrun changes of climate as both challenges look as if sharing similarities. Both shall necessitate a significant threshold of global collaboration. The two of them required radical behavioral changes in today's practices to reduce tomorrow suffering. It has been pointed out and predicted for a long time back, with obvious certainty by scientists, nevertheless have been ignored by official authorities, who were unable to look beyond the nearest fiscal quarter's growth statistics. Accordingly, both will require governments to take drastic action and banish the logic of the marketplace from certain realms of human activity, while simultaneously embracing. Now the challenge is to maintain crisis signs activated about climate, while the risks are orders of magnitude greater. It is not feasible to believe that we can't go 'back to normal', as all things weren't so." the burdens of climate change are more gradual than those of Covid-19. Most people do not feel they or their loved ones could die from the climate crisis this month, and so emergency mode is harder to activate and sustain., if we really believe that we are in a climatic crisis, The news continuously updating about which countries 


\section{Epidemiology International Journal}

were declining their emissions the fastest, and people are clamoring to be certain that their leaders were implementing the policies that operating out effectively.

\section{Understanding Contexts}

However, it is not unimaginable that the experience of Covid-19 could help us understand climate change differently. One of the good side products of the present crisis is the significant reduction of road traffic and manufacturing activities, air pollution has plummeted, a particularly harmful pollutant that attacks the heart and lungs. It is estimated that, in China alone, emission reductions since the start of the pandemic had in effect saved the lives of at least 1,400 children under five and 51,700 adults over 70 . Meanwhile, people around the world have been sharing their own anecdotal findings online - stories of sweet-smelling breezes, expanded bike lanes, and birdsong returning to neighborhoods -people catching signs, in the midway of catastrophe, about known and wanted future.

\section{Hope Signs}

In parallel to all hopeful signs, which fits Covid-19? Disaster, the dismantling of even the meager currently applied rules designed to protect the atmosphere. In realizing the effect of the pandemic on the workforce, violation of pollution regulation will not be punished as far as firms can link likewise violations to the Covid19 emergency. Ministry of Environment in china already began waiving such monitoring, which evaluate the environmental burdens of industrial factories. In addition, advocacy groups funded by the plastics industry have launched a public relations blitz on behalf of single-use plastic bags, spreading the unproven claim that the virus has a low probability to adhere to plastic compared to fabric clothes of reusable bags. During the 2008 crisis, the emissions dropped down significantly, yet rebounded remarkably in 2010-2011.

\section{Lessons Learned}

One of the brilliant lessons of the covid19 emergency is the energy of shared thoughts and emotions, which has accelerated radical reaction to bring the pandemic spread down. ".Lessons learned by humanity is that world need to experience fear and to be shocked enough at whole, to ready to react sufficiently to what we're scare with. Thus, solely governments can be obliged to do. "It's truly of maximum privilege to experiencing dangerous moments to have good insight," the principle that we need to apply to climate as well. It is clear to everybody that the Covid19 pandemic showed the utter bankruptcy of specific approaches to the economy "full of loss and vagueness." Can we stop the world from going back to a version prior to Covid-19, the progress in beating Covid19 still need more focusing without forgetting old ongoing disasters that are not yet unfolded?

\section{Epidemic Outcome}

"The political outcome of the epidemic needs to get analysis out in the world any way we can." One major obstacle is social distancing, which certainly hinders many time-tested methods of struggling and street protesting and canvassing. "The biggest risk this time" "exclusion people, leave them sitting home, excessively handling social media, and extremely restricted forms to politics forms that get there enabled."

'It's knife's edge we're walking at ':

What will evolve next, might link to the optimists' capacity to translate such times of Coalescence into the wider political horizon, debating that it brings no sense to handle Covid-19 beyond fixing everything else, to sharing resources with more people. "There is no language for this emotion, in which the wonderful comes wrapped in the terrible, joy in sorrow, courage in fear," it is like Paradise Built in Hell. "It is not possible to welcome disaster, but the responses can be valued, both practical and psychological." The world feels awfully strange right now, but not solely because -- it is fastly changing so fast and any one of and no one could fall sick at any moment, or carrying already the virus without knowing. The last few months of the Covid19 pandemic experienced extremely strange through uncovering a truth that, major events can possibly be changed, at any time. This truth, keep threatening both stability and liberty, can be simply forgotten. We are not observing a movie: we are contributing to the end together.

\section{Bibliography}

1. Abdullah Z (2020) COVID-19 to have 'significant' impact on economy: PM Lee Hsien Loong. CNA.

2. Tiezzi S (2020) China and Cambodia: Love in the Time of Coronavirus. The Diplomat.

3. Limited Bangkok Post Public Company (2020) Baht hits 7-month low as China virus threatens tourism. Bangkok Post.

4. Mufti RR (2020) 10,000 Chinese tourists cancel trips to Bali over coronavirus fears: Travel group. The Jakarta Post.

5. The Jakarta Post (2020) Panic buying hits Jakarta supermarkets as govt announces first COVID-19 casesCity. The Jakarta Post.

6. Kana G (2020) Wuhan virus fears infect Malaysian 


\section{Epidemiology International Journal}

economy. The Star.

7. Long J (2020) Coronavirus sees Chinese teams pull out of Tour de Langkawi and all riders subjected to healthscreenings. Cycling Weekly.

8. Chaw K (2020) List of KL concerts postponed due to
Covid-19. The Star.

9. Saudi Arabia halts travel to Mecca, Medina over coronavirus.

10. Singh M (2020) MWC hangs by a thread after Nokia, DT and other big names back out. Tech Crunch. 